\title{
O CARÁTER SUBSTANCIAL DOS ORGANISMOS VIVOS EM Aristóteles
}

\author{
Rodrigo Romão de Carvalho ${ }^{1}$
}

\begin{abstract}
Resumo: Neste artigo, procura-se analisar os fatores envolvidos na determinação da natureza substancial do organismo vivo, em Aristóteles. Tais fatores seriam, por um lado, a forte unidade e coesão interna composicional e, por outro, o elevado caráter de independência quanto às propriedades essenciais ou formais, relativamente às propriedades dos componentes materiais, por meio dos quais o organismo vivo vem a ser formado, ou com referência aos outros tipos de particularidades de seres. Com esta análise, pretende-se mostrar, ao mesmo tempo, que a unidade do composto orgânico-animado, de um modo geral, é constituída por um complexo arranjo de camadas estratificadas (elementos, partes homogêneas, partes nâo homogêneas), no qual as camadas ou os tipos de composiçôes materiais apresentam, entre si, um forte grau de interdependência. Tal interdependência entre as partes materiais, que formam uma rede composicional complexa e bem-articulada, faz com que as propriedades essenciais ou formais do todo orgânico se diferenciem sobremaneira das propriedades essenciais dos tipos de componentes que integram esse todo, caracterizando, assim, o caráter substancial da composiçấo orgânica.
\end{abstract}

Palavras-Chave: Substância. Organismo vivo. Unidade. Independência Composicional. Aristóteles.

\section{INTRODUÇÁO}

O caráter distintivo da constituição orgânica em Aristóteles é conferido pelo fato de essa constituição apresentar uma existência (i) individual e (ii) independente (METAFÍSICA, V. 8, 1017b25²). Tal existência é notadamente

${ }^{1}$ Doutor em Filosofia pelo Departamento de Filosofia, da Faculdade de Filosofia, Letras e Ciências Humanas da Universidade de São Paulo (USP), São Paulo, SP - Brasil. (D) https://orcid.org/00000002-9583-9073 Email: romaodc@gmail.com

${ }^{2}$ Nessa passagem, Aristóteles vale-se das expressōes (i) tóde ti e (ii) khoristòn, as quais, de uma maneira literal, poderiam ser traduzidas por (i) "um isto" e por (ii) "separado". Entendo que "um isto" e "separado" remeteriam, de um modo direto, às ideias ou aos sentidos de, respectivamente, "algo uno" ou "uma unidade", e "o que é independentemente de outra coisa", justamente por ser separado. Penso que tais expressôes, além disso, estariam estreitamente vinculadas à noçâo de forma ou de essência, uma vez que aquilo que define "o que algo é" é a sua natureza própria, específica, ou seja, algo que é uno e independente de outras características.

http://doi.org/10.1590/0101-3173.2020.v43n2.15.p281

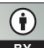

This is an open-access article distributed under the terms of the Creative Commons Attribution License. 
marcada pela noção de homonímia. Em linhas gerais, a noção de homonímia estipula que as partes das quais o ser vivo é composto somente são definidas como tais, na medida em que desempenham ou são capazes de desempenhar as suas atividades ou funçôes próprias ${ }^{3}$, a partir de certo arranjo composicional apropriado.

O todo orgânico não constitui uma mera soma de suas partes, pois a proporção e limite de seu tamanho, ou seja, a sua configuração (schêma) não é determinada por uma simples conjunção espontânea de séries causais, ocasionada por interaçóes entre os movimentos dos componentes materiais. A devida configuração, ou arranjo disposicional de suas partes, isto é, o modo como as partes são concatenadas para poder realizar certa função, ou um conjunto articulado de funçóes, é promovida pelo princípio formal do organismo, de modo que o todo orgânico vem a ser algo distinto daquilo de que é constituído ${ }^{4}$.

Por isso, segundo Aristóteles, Demócrito não se pronunciou corretamente, ao identificar a forma com as configuraçóes externas dos seres vivos, apreensíveis pelos sentidos. A esse respeito, é possível ler, no Livro I das Partes dos animais (I.1, 640b29-641a5, tradução nossa) ${ }^{5}$ :

Se cada um dos animais e de suas partes fosse pela figura e pela cor, Demócrito teria se pronunciado de maneira correta: pois parece que ele assim pensou. Em todo caso, ao menos, ele afirma que a qualquer um é evidente de que qualidade é o homem em sua forma, ao ser reconhecido pela figura e pela cor. No entanto, também o homem morto possui a mesma forma de configuração, mas, no entanto, não é um homem. Além do mais, é impossível haver uma mão disposta de qualquer maneira que

\footnotetext{
${ }^{3}$ Cf. Meteorológicos, IV.12, 389b31-390a2; De Anima, II.1, 412b11-15, 19-21; Geraçāo dos animais, I.19, 726b22-24, II.1, 734b25-27, 735a8-9, II.5, 741a10-13; Metafísica, VII.10, 1035b23-25.

${ }^{4}$ Em uma passagem da Geração e corrupção, Aristóteles escreve o seguinte: "Dado que há entes que são em potência e entes que são em ato, é possível que as coisas combinadas sejam em um sentido e, em outro sentido, náo sejam, resultando o produto de sua combinaçấo diverso delas em ato, mas podendo cada ingrediente ser em potência o que era antes de se combinar, e não ser destruído" (Geração e corrupção, I.10, 327b23-26). O que Aristóteles pretende dizer, nessa passagem, é que a combinação que resulta na constituição dos organismos é, em ato, algo distinto dos elementos materiais da qual é composta, mas esses elementos não deixam de preservar em si e por si mesmos, em potência, as suas características essenciais. Desse modo, as coisas combinadas enquanto tais são, e náo são, na medida em que as suas partes constituintes deixam de ser o que sáo em ato, e passam a ser em potência em relação ao todo do qual são partes.

${ }^{5}$ Com relação às citaçôes das obras de Aristóteles traduzidas para o português, utilizei a edição "Bekker I", as traduçōes para o inglês, as edições bilíngues da "Loeb Classical Library", as traduçóes para o espanhol, as ediçôes "Gredos", e as traduçôes para o português, de L. Angioni, dos Livros I e II da Física e do Livro I das Partes dos animais.
} 
houver, por exemplo, uma de bronze ou uma de madeira, a não ser por homonímia, tal como o médico desenhado. Pois ela não seria capaz de efetuar sua função própria [...]. E semelhantemente a estes casos, nenhuma das partes de um morto seria propriamente tal, quero dizer, por exemplo, olho, mão ${ }^{6}$.

Para Aristóteles, uma mão - ou qualquer que seja a parte do organismo - só é o que é em função do todo orgânico do qual faz parte. A mão separada do corpo, ou a mão de um homem morto, só se diz mão por homonímia, tal como uma mão pintada ou esculpida, pois ela não desempenha a função que a caracteriza enquanto tal, e pela qual definimos o que ela é. Da mesma maneira, um homem morto pode apresentar um mesmo formato externo de um homem vivo, enquanto se mantém de alguma forma preservado, ou enquanto não aparenta estar se decompondo. Todavia, um homem morto não é, de fato, um homem, a não ser por homonímia.

O que distingue o homem é justamente a sua capacidade de executar determinadas funçóes próprias, e que o habilita a desempenhar certas atividades características como, entre outras, a nutrição, a respiração, o crescimento, a sensação, a locomoção etc. Assim, conforme Aristóteles, não se deve pensar em um organismo vivo em termos de configuração externa - como Demócrito equivocadamente supunha, ao pretender que o homem poderia ser conhecido "pela figura e pela cor" (toi schémati kai toi chrómati) -, mas sim em termos de função, ou conjunto articulado de funçôes, em vista do qual ele vem a ser como tal e pelo qual apreendemos a sua definição, o seu logos.

Nessa perspectiva, os ossos de uma ossada, por exemplo, podem até preservar durante muito tempo uma mesma configuração estrutural e uma semelhante disposição material, mas, apesar disso, eles não são mais de fato ossos - eles só são ditos "ossos" por homonímia (com relação ao dedo, ver: METAFÍSICA, VII.10, 1035b24-25), visto que perderam a capacidade de executar as suas funçóes características e essenciais, por meio das quais os definimos. Tais funçôes são as seguintes: tornar possível a flexão do corpo, por

\footnotetext{
${ }^{6}$ Ei mèn oûn tôi skhémati kaì tôi khrómati hékastón esti tôn te zóion kaì tôn morion, orthôs àn Demókritos légoi: phainetai gàr hoútos hupolabeîn. Phesi goûn pantì dêlon eînai hoîon ti tèn morphén estin ho ánthropos, hos óntos autoû tôi te skhémati kai tôi khrómati gnorímou. Kaitoi kai ho tethneòs ékhei tèn autèn toû skhématos morphén, all'hómos ouk éstin ánthropos. Éti d'adúnaton eînai kheîra hoposoûn diakeiménen, oîon khalkên è xulinen, plèn homonúmos, hósper tòn gegramménon iatrón. Ou gàr dynésetai poieîn tòn heautês érgon [...]. Homoíos dè toútois oudè tôn tồ tethnekótos morion oudèn éti tôn toioúton estí, légo d'hoîon ophthalmós, kheir.
} 
meio de suas articulaçóes, juntamente com a carne a eles anexada, através de ligaduras leves e fibrosas, e proteger os órgãos internos, como, por exemplo, as costelas que envolvem o peito, ao servir de proteção às vísceras em torno do coração (PARTES DOS ANIMAIS, II.9, 654b27-655a2).

O osso e a carne, sendo compostos homogêneos, possuem cada qual determinadas qualidades e afecçóes próprias, como dureza, fragmentação, brandura, tensão etc., decorrentes de certas interaçôes entre os componentes elementares, em função de suas propriedades essenciais, tais como o calor, o frio, e dos movimentos gerados por eles:

Tais partes [sc. homogêneas], entáo, podem gerar-se por meio do calor e do frio, e pelos movimentos produzidos por eles, uma vez que são solidificadas pelo calor e pelo frio: refiro-me a todas as partes homogêneas, como a carne, osso, o cabelo, o tendáo e similares; todas, pois, se distinguem pelas diferenças mencionadas: tensão, ductilidade, fragmentabilidade, dureza, maleabilidade e as demais deste tipo; estas surgem por meio do calor, do frio e dos seus movimentos combinados (METEOROLÓGICOS, IV.12, 390b2-9. Tradução nossa.) ${ }^{7}$.

No entanto, dado que o osso, na composição orgânica, está intimamente vinculado a outros ossos e à carne a ele ligada, em virtude da natureza orgânicoformal do animal, as diferentes qualidades e afecçóes próprias dessas partes seriam, por isso, subsumidas ao todo composicional, a fim de que seja possível a flexão corporal.

\section{$1 \mathrm{O}$ TODO ORGÂNICO}

O organismo vivo como um todo é capaz de realizar o conjunto articulado de funçôes que o caracteriza como tal, na medida em que vem a ser constituído por um complexo arranjo material de camadas estratificadas, envolvendo três tipos de composição: (i) a que corresponde aos elementos: fogo, ar, água e terra; (ii) as partes homogêneas (homoiomeres): sangue, carne, ossos etc.; (iii) as partes não homogêneas (anhomoiomeres): mãos, olhos,

\footnotetext{
7 Tà mèn oûn toiaûta mória thermóteti kai psukhróteti kai taîs hypò toúton kinésesin endékhetai gígenesthai, pegnúmena tôi thermôi kai tôi psukhôi: légo d'hósa homoiomerê, hoîon sárka, ostoûn, tríkhas, neûron, kai hósa toiaûta; pánta gàr diaphérei taîs próteron eireménais diaphoraîs, tásei, hélxei, thraúsei, skleróteti,

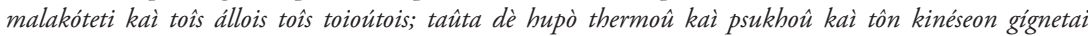
meignuménon.
} 
pulmôes ${ }^{8}$ etc. (GERAÇÃO DOS ANIMAIS, I.1, 715a9-12; BOGEN, 1996, p. 183-184). O primeiro nível de composição orgânica serve de base para a composição de todos os outros níveis constituintes, mas, de um modo mais imediato, se apresenta como componente material das partes homogêneas. Já as partes homogêneas, formadas pelos quatro elementos, funcionam como componentes das partes não homogêneas, enquanto estas, por sua vez, constituem a composiçáo do ser vivo como um todo (PARTES DOS ANIMAIS, II.1, 646b5-8). Assim, pode-se notar que a constituição orgânica é disposta por certas camadas composicionais, de maneira que os níveis de composição inferiores servem de matéria para os níveis de composição situados nas camadas superiores:

O úmido, o seco, o quente e o frio ${ }^{9}$ sáo matéria dos corpos compostos [...]. A segunda composiçáo dos primeiros elementos constitui, nos seres vivos, as partes homogêneas, como o osso, a carne e as outras partes semelhantes. A terceira, e última quanto ao número, é a das partes não homogêneas, como o rosto, a máo e as partes semelhantes (PARTES DOS ANIMAIS, II.1, 646a16-24, tradução nossa. $)^{10}$.

Dentre os três tipos de composição que, de certa forma, podem ser designados como matéria do organismo, somente o primeiro, correspondente aos quatro elementos, pode existir à parte do ser vivo. As partes homogêneas e não homogêneas, distintamente dos elementos, não se encontram na natureza aquém e além da existência do organismo vivo. Ossos, carne, mãos, olhos etc. vêm a ser e são definidos estritamente pela funçáo que eles exercem no organismo como um todo ${ }^{11}$. Assim, eles não são o que são sem o organismo

8 As partes homogêneas e as partes não homogêneas, respectivamente, corresponderiam, mais ou menos, à nossa distinção entre tecidos e órgãos.

9 Nesse trecho, no lugar de mencionar os quatro elementos - (i) fogo, (ii) ar, (iii) água e (iv) terra -, Aristóteles cita os tipos de propriedades essenciais que caracterizam os componentes elementares. $\mathrm{O}$ (i) fogo é caracterizado por ser quente e seco, o (ii) ar, quente e úmido, a (iii) água, fria e úmida e a (iv) terra, fria e seca (Geração e corrupção, II.3, 330b3-5). No entanto, levando-se em conta outras passagens das obras aristotélicas, é mais comum a menção dos quatro elementos, ao invés de suas propriedades essenciais, a fim de se referir aos componentes materiais que constituem a base, não somente das partes que compóem os organismos vivos, mas, de um modo geral, de todos os compostos ou substâncias naturais. Ver, por exemplo: Partes dos animais, I.1, 640b8-11; II.1, 646b5-8; Geraçấo e corrupção, II.8, $334 \mathrm{~b} 32$ e ss.; Meteorológicos, IV.12, 389b26-28.

${ }^{10}$ Hugròn gàr kaì xeròn kai thermòn kaì psúkhon hýle tôn sunthéton somáton estín [...]. Deutéra dè sústasis ek tôn próton he tôn homoiomerôn phýsis en tồs zóiois estín, hoîon ostồ kaì sarkòs kaì tôn állon tôn toioúton. Trite dè teleutaía kat'arithimòn he tôn anomoiomerôn, hoîon prosópou kaì kheiròs kaì tôn toioúton morion.

${ }^{11}$ Com relação aos ossos e às veias, ver: As Partes dos Animais, II.9, 654a32-654b12. 
do qual fazem parte (METAFÍSICA, VII.10, 1035b23-25). Enquanto caracterizados como tais, as partes homogêneas e as partes não homogêneas estabelecem uma relação de caráter necessário e de interdependência com a natureza formal do animal.

\section{AS PARTES COMPOSICIONAIS DO ORGANISMO VIVO}

Entre os elementos que compóem a matéria apropriada do ser vivo (partes homogêneas e não homogêneas) e, de um modo geral, a forma do animal, há uma relação de caráter contingente, pois os elementos, na composição orgânica, adquirem propriedades acidentais para se tornarem aptos a exercer as funçóes requeridas pelo vivente. Considerados em si mesmos, os elementos possuem propriedades essenciais, as quais, por meio de uma intervenção externa a eles próprios, vêm a adquirir novas propriedades. Contudo, essas propriedades essenciais dos elementos permanecem em potência na compleição do vivente. Um sinal disto é que, no processo de decadência ou deterioração do animal, as propriedades acidentais que os elementos apresentam, ao compor o organismo, passam a deixar de atuar em função das propriedades essenciais que esses elementos, por si mesmos, preservavam na forma de disposiçôes ${ }^{12}$. A esse respeito, Aristóteles (DE CAELO, II.6, 288b14-18, tradução nossa) assevera:

As debilidades, nos animais, são contra a natureza, como a velhice e o enfraquecimento. Pois, certamente, a constituição inteira dos animais está formada a partir de [elementos] tais que diferem de seus lugares próprios; pois nenhuma das partes ocupa o lugar que é próprio a ela mesma. ${ }^{13}$

\footnotetext{
12 Waterlow afirma: "Os elementos no contexto biológico, ou totalmente deixam de lado suas naturezas originais, ou são modificados de modo a se adequarem às necessidades do todo. Na primeira alternativa, eles não estão absolutamente presentes no organismo [...]. $\mathrm{Na}$ segunda alternativa, enquanto os elementos puderem, em certo sentido, estarem lá, os modos nos quais manifestam a sua presença são dedutíveis apenas de um conhecimento prévio do organismo e suas necessidades, e não vice-versa" (Waterlow, S., 1982, p. 86). Para Waterlow, os elementos, ao constituírem os organismos vivos, perderiam as suas disposiçôes essenciais. Entretanto, essas disposiçóes são, justamente, o que explicaria a decadência ou a deterioração do animal.

${ }^{13}$ Hai en toîs zóiois adunamíai pâsai parà phisen eisin, hôion gêras kaì phthisis. Hóle gàr ísos he súsasis tôn zóion ek toióuton sunéseken hà diaphérei tô̂s oikeiois tópois; outhèn gàr tôn merôn ékhei tèn hautôi khóran.
} 
Ao formarem os animais, os elementos permanecem, sob a intervenção da natureza formal do ser vivo ${ }^{14}$, fora de seus lugares naturais. Assim, as disposiçóes originais dos elementos são constrangidas, de sorte que a tendência de voltarem a essas disposiçôes originais explica as debilitaçóes que os animais inevitavelmente sofrem, aumentando gradativamente no decorrer do tempo ${ }^{15}$. $\mathrm{O}$ fato de que os elementos - cessada a intervenção externa que mantinha as suas propriedades essenciais desatualizadas no organismo - tendem a voltar a se comportarem segundo as suas respectivas naturezas, revela o caráter contingente da relação entre os elementos no seu estado primitivo e as propriedades adquiridas através da forma do organismo.

Os elementos tomados em si mesmos, então, mantêm uma relação de caráter contingencial relativamente às partes do ser vivo e ao organismo como um todo. No entanto, vimos que o mesmo não se dá com relação às partes homogêneas e às partes não homogêneas, visto que tais partes dependem do todo substancial para existirem, de modo que elas são definidas e são essencialmente como tais, em função da compleição orgânica. Há, portanto, uma forte relação de interdependência entre as partes e o todo, mas, também, entre as partes homogêneas e as partes não homogêneas. Um sinal disso seria a presença de certas disposiçóes composicionais estruturadas de tal maneira a configurar uma espécie de interface entre as partes homogêneas e as partes não homogêneas.

Como M. Furth observou, há determinados tipos de "partes" intermediárias entre, por exemplo, a partes que compóem o coração (FURTH, 1988, p. 34-36): ele "é divisível em partes homogêneas, como cada uma das outras vísceras, porém, pela forma de sua configuração, é não homogêneo" (PARTES DOS ANIMAIS, 647a31-33). Enquanto composto de carne, o coração é uma parte homogênea, mas, na medida em que apresenta certo arranjo morfológico, para que possa desempenhar adequadamente a sua função, no organismo vivo, ele se manifesta como uma parte não homogênea.

\footnotetext{
${ }^{14}$ A natureza formal do organismo vivo corresponde à alma, que se expressa por um conjunto articulado de funçōes vitais. Sobre o assunto em questão, vemos a seguinte passagem do De anima: "O que manteria juntos a terra e o fogo, que se deslocam para lugares contrários? Pois ambos se dispersariam, se não houvesse algo que impedisse. Mas, se há algo que impede, é a alma que é isso, assim como a causa do crescer e alimentar-se." (De anima, II.4, 416a6-9).

${ }^{15}$ A esse respeito, Whiting escreve: "Os organismos vivos envelhecem e decaem, porque os elementos que os constituem tendem a se moverem para os seus lugares naturais - fogo para o alto e terra pra baixo - com o resultado que os elementos, gradualmente, vêm a se separarem uns dos outros, e deixam de estarem presentes nas proporçôes necessárias à existência das partes homogêneas." (WHITING, J. E., 1992, p. 82-83).
} 
Talvez esse ponto se torne mais claro na seguinte passagem (PARTES DOS ANIMAIS, II.9, 654a32-654b13, tradução nossa):

A natureza dos ossos e das veias é similar. Ambos formam um sistema contínuo surgido de um princípio único, e nenhum osso existe por si mesmo, senão que, ou bem é como uma parte de um contínuo, ou bem está em contato e ligado a este, para que a natureza se sirva dele tanto como de um osso único e contínuo, tanto como de dois e divididos para facilitar a flexão. De igual modo, tampouco nenhuma veia existe por si mesma, senão que todas são parte de uma. Um osso, de fato, se fosse algo separado, não poderia cumprir a função para qual está destinada sua natureza (pois não poderia ser causa de nenhuma flexão nem extensão sendo descontínuo ou separado), e inclusive faria dano como um espinho ou uma flecha na carne. Similarmente, se uma veia estivesse separada e não unida a seu princípio, não poderia conservar o sangue que contém. O calor procedente daquele princípio impede que se coagule, e é evidente que o sangue separado se corrompe. O princípio das veias é o coraçáo, dos ossos, naqueles animais que os têm, é a chamada coluna vertebral, da qual surge a estrutura contínua dos outros ossos. ${ }^{16}$

Os ossos e as veias, visto que são tomados individualmente, se mostram como partes homogêneas, mas, enquanto considerados como componentes de uma estrutura maior, levando-se em conta a conexão que há entre os ossos, em particular, e entre as veias, em particular, eles se apresentam como partes não homogêneas. Os ossos, no organismo vivo, estáo essencialmente ligados uns aos outros, formando um sistema contínuo cujo princípio é a coluna vertebral (rákhis). E é necessário que eles se disponham de tal e tal modo, a fim de que seja possível a realização das funçóes pelas quais vieram a ser constituídos e pelas quais são definidos essencialmente como tais.

De uma forma semelhante, as veias formam uma rede interligada e contínua que se origina no coração (Partes dos animais, III.5, 667b16-20). Se assim não fosse, não seriam capazes de preservar as propriedades essenciais

\footnotetext{
${ }^{16}$ Ékhei d'homoíos he te tôn ostôn kaì he tôn phlebôn phýsis. Hékatera gàr autôn aph'henòs ergméne sunekhés esti, kaì oút'ostoûn estin auto kath'hautò oudèn, all'è mórion hos sunekhoûs è haptómenon kaì prosdedeménon, hína khêtai he phýsis kaì hos henì kaì sunekheî kaì hos dusì kaì dieireménois pròs tèn kámpsin. Homoíos dè kaì phlèps oudemía autè kath’hautén estin, Allá pâsai mórion mias esisin. Ostoûn te gàr eí ti kekhorisménon ên, to t'érgon ouk àn epoíei hoû khárin he tôn ostôn esti phýsis (oúte gàr àn kámpseos ên aítion oút'oerthótetos oudemiâs mè sunekhès òn allà dialeîpon), étit'éblapten àn hósper ákhanthá tis è belos enòn taîs sarxín. Eíte phlèps ên tis kekhorisméne kaì mè sunekhès pròs tèn arkhén, ouk àn ésoze to em hautêi aîma. He gàr ap'ekeínes thermótes kolúei pégnusthai, phaínetai dè kà̀ sepómenon to khopizómenon. Arkhè dè tôn mèn phlebôn he kardía, tôn d'ostôn he kalouménon rákhis toîs ékhousin ostâ pâsin, aph’hês sunekhès he tôn állon ostôn esti phýsis.
} 
do sangue contido nelas, para conduzi-lo a todas as partes orgânicas, a fim de nutri-las (GERAÇÃO DOS ANIMAIS, II.6, 743a8-10). É necessário que as veias estejam conectadas ao coração, que lhe fornecem o calor vital, sem o qual não haveria a manutenção das características próprias do sangue, pois, sob o efeito do calor vital, ele é quente e líquido, todavia, ao se separar, é frio e sólido (PARTES DOS ANIMAIS, II.3, 649b27-30).

\section{CONSIDERAÇÓES FINAIS}

Dadas tais considerações a respeito do complexo composicional da substância orgânico-animada, penso que, com base na perspectiva aristotélica, a composição orgânica não poderia ser o resultado de uma combinação efetuada exclusivamente pelos movimentos resultantes das propriedades essenciais dos elementos. Se assim fosse, não seria possível explicar (i) por que de um animal proviria, com regularidade, outro de mesmo espécime, (ii) por que, constantemente, ocorreria a formação de certas disposiçóes composicionais ajustadas à realização das atividades vitais e (iii) por que as distintas partes do ser vivo, no mais das vezes (hôs epi to poly) ${ }^{17}$, viria a ocupar em diversos indivíduos semelhantes posiçóes na compleição do corpo $^{18}$.

Nesse sentido, segundo Aristóteles, Empédocles procurava desacertadamente se valer apenas de causalidades de tipo materiais e eficientes associadas aos componentes materiais, autonomamente ligadas entre si por uma relação de concomitância, a fim de explicar, por exemplo, a composiçáo da coluna vertebral no processo gerativo de um organismo vivo:

\footnotetext{
${ }^{17}$ Essa expressão aristotélica refere-se aos eventos que sucedem com regularidade, mas que não deixam de comportar poucas exceçóes que fogem à regra.

18 Para ilustrar esse ponto, Pellegrin recorre a termos e expressôes anacrônicas, tais como "ação mecânica" e "propriedades físico-químicas": "É impossível que, deixadas à ação mecânica que resulta de suas propriedades físico-químicas, os elementos materiais se organizem espontaneamente em uma estrutura estável táo complexa quanto àquela do ser vivo." (PELLEGRIN, 1995, p. 29). A ideia geral de que a natureza poderia ser explicada em termos de açôes mecânicas é mais propriamente do século XVII, e a noção de propriedades físico-químicas é ainda mais recente. Mas, o que Pellegrin pretende dizer com (i) açôes mecânicas e (ii) propriedades físico-químicas é que (i) o concurso espontâneo das séries causais que resultam (ii) das propriedades essenciais dos elementos, por si só, seria incapaz de explicar o estável e complexo arranjo composicional que os seres vivos comportam.
} 
Empédocles não se pronunciou corretamente ao afirmar que muitos itens pertencem aos animais porque assim sucedeu concomitantemente no vir a ser; como, por exemplo, ter a espinha de tal e tal qualidade porque, ao se retorcer [sc. o corpo], sucedeu-lhe concomitantemente quebrar-se - ele não reconheceu, primeiramente, que é preciso que o esperma constituidor esteja já disposto no começo com uma capacidade de tal e tal tipo e, em seguida, que o produtor se apresente como anterior não apenas por definição, mas também no tempo: pois é um homem que gera um homem, de modo que é porque aquele homem é de tal e tal qualidade que o vir a ser sucede assim de tal modo para este outro (PARTES DOS ANIMAIS, I.1, 640a19-27. Tradução nossa). ${ }^{19}$

Para Empédocles, seria suficiente, pois, descrever a atividade gerativa da espinha dorsal recorrendo tão somente aos movimentos absolutamente necessários dos componentes materiais, os quais se realizam de uma maneira espontânea. Nessa perspectiva, seria em função de a coluna vertebral ser constituída por certa composição material, somado ao fato de o embriấo, de um modo casual, contorcer-se várias vezes, que a coluna manifestaria determinadas características, isto é, que ela se apresentaria como um conjunto de vértebras articuladas. Assim, a função empreendida pela espinha dorsal, no organismo vivo como um todo, seria em virtude de um simples efeito espontâneo dos movimentos intrinsecamente ligados aos elementos materiais. Entretanto, Aristóteles pondera que, embora necessárias, as causalidades de tipo materiais e eficientes não seriam plenamente suficientes para explicar os devidos engendramentos das partes constituintes de um organismo vivo; pelo contrário, seria preciso servir-se de causas formais e finais, as quais direcionariam, de certa forma, o conjunto de causas materiais e eficientes sob a determinação de uma articulação de interdependência entre elas, de maneira a possibilitar ao ser vivo a execução efetiva de suas funções vitais características.

A posição que Aristóteles atribui a Empédocles, mas que também poderia ser atribuída a Demócrito, ou, de um modo mais geral, aos filósofos naturalistas do século V a.C., os denominados physiologoi ${ }^{20}$, estabelece que

${ }^{19}$ Empedoklês ouk orthôs eirreke légon hupárkhein pollà toîs zóios dià tò sumbênai hoútos en têi genései, hoîon kaì tèn rhákhin toiaúten ékhein hóti straphéntos katakhthênai sunébe, agnoôn prôton mèn hóti deî tò spérma tò sunistàn húparkhein toiaúten ékhon dýnamin, eîth’hóti tò poiêsan próteran hupêrkhen ou mónon tôi lógoi allà kai tôi khónoi: gennâi gàr ho ánthropos ánthropon, hóste dià tò ekeînon toiónd'einnai he génesis toiáde sumbainei toidí.

${ }^{20}$ Aristóteles alega que a maioria dos filósofos naturalistas do século $\mathrm{V}$ a.C. confere unicamente a fatores materiais, e às propriedades essenciais a eles atinentes, os princípios através do quais a totalidade dos seres naturais, incluindo os organismos vivos, vêm a se constituir. Desse modo, a verdadeira natureza 
a adequada encadeação dos conjuntos de causalidades materiais e eficientes se realizaria por meio de açóes espontâneas, por causa tão somente de uma interação contingente entre os elementos, em razão de suas predisposições essenciais (FÍSICA, II.8, 198b23-31). Certamente, Aristóteles não aceitará esse posicionamento, pois, para ele, a apropriada conexão dos conjuntos de causas materiais e eficientes, pela qual o vivente vem a ser formado, não poderia realizar-se unicamente por relaçóes fortuitas da matéria elementar.

Antes, esses conjuntos causais se arranjariam de uma maneira própria, através de causas formais e finais, as quais operariam sob o pressuposto de um princípio anterior, ou de um elemento teleológico, fazendo com que os componentes dos elementos materiais redirecionem o curso espontâneo de suas disposições essenciais e, em função desse redirecionamento, obtenham propriedades acidentais, as quais possibilitariam aos organismos vivos a efetivação de suas funçóes naturais. Os movimentos espontâneos da matéria elementar seriam, então, apropriadamente ordenados e encadeados por um fator teleológico de natureza formal, o qual não operaria senão por intermédio da atividade seminal, envolvida no processo reprodutivo, e não por alguma entidade misteriosa ou instância sobrenatural (NUSSBAUM, 1985, p. 60; ANGIONI, 2000, p. 162).

Por conseguinte, a constituição orgânica exibiria tanto individualidade, pelo fato de suas partes constituintes apresentarem entre si uma forte relação de interdependência, quanto (ii) independência, na medida em que os fatores materiais das propriedades próprias dessas mesmas partes seriam subsumidos pelos fatores formais do organismo, em razão de suas propriedades morfofuncionais. No exemplo mencionado anteriormente, o osso (ou os ossos) e a carne, sendo corpos homogêneos de naturezas distintas, apresentam-se na constituição orgânica como uma unidade individual coesa e indissociável. Além disso, o osso e a carne manifestam outras propriedades independentes daquelas que tais corpos homogêneos exibem, enquanto analisados em separado, ou seja, o osso é relativamente duro, fragmentável etc., e a carne é relativamente maleável, tensa etc., porém, no organismo vivo, são definidos segundo suas capacidades de possibilitar a flexão corporal e de proteger os órgãos internos.

de todas as coisas corresponderia ao(s) elemento(s), por meio do qual elas são primeiramente geradas, e, ulteriormente, vêm a se dissociar (Metafísica, I.3, 983b6-11). Segundo Aristóteles, Anaxágoras de Clazômenas, por exemplo, defendia que os primeiros princípios eram infinitos, e que os entes naturais eram gerados e destruídos através exclusivamente de causas materiais, por um processo de mera agregação e desagregação (Metafísica, I.3, 984a11-19). 
CARVALHO, R. R. The substantial feature of living organisms in Aristotle. Trans/ form/ação, Marília, v. 43, n. 2, p. 281-294, Abr./Jun., 2020.

\begin{abstract}
AвSTRACT: In this paper, I will try to analyze the factors involved in determining the substantial nature of the living organism in Aristotle. Such factors would be, on the one hand, the strong unity and compositional internal cohesion and, on the other hand, the high character of independence as regards the essential or formal properties, relative to the proper properties of the material components through which the living organism comes to be formed, or relative to other types of particularities of beings. With this analysis, it is intended at the same time to show that, in a general way, the unity of the organic-animate compound is constituted by a complex arrangement of stratified layers (elements, homogeneous parts, nonhomogeneous parts), in which the layers or types of material compositions have a strong degree of interdependence among themselves. Such interdependence between the material parts, which form a complex and well-articulated compositional network, makes the essential or formal properties of the organic whole very different from the essential properties of the types of components that make up the whole, thus characterizing the substantial character of organic composition.
\end{abstract}

KeYwords: Substance. Living Organism. Unity. Compositional Independence. Aristotle.

\title{
REFERÊNCIAS
}

ANGIONI, Lucas. O hilemorfismo como modelo de explicaçáo científica na filosofia da natureza em Aristóteles. Belo Horizonte: Kriterion, vol. XLI, no. 102, p. 136 - 164, 2000.

ARISTÓTELES. Aristotelis Opera. BEKKER, I-II. (ed.), Academia Regia Borussica, Vols. I-II, Berlim, 1831.

ARISTÓTELES. The metaphysics. Books I-IX.Trad.: H. Tredennick, London: The Loeb Classical Library, 1947.

ARISTÓTELES. Meteorologica.Trad.: H. D. P. Lee. London: The Loeb Classical Library, 1952.

ARISTÓTELES. On sophistical refutations. On Coming-to-be and Passing Away; On the Cosmos. Trad.: E. S. Foster, and D. J. Furley, London: The Loeb Classical Library, 1955.

ARISTÓTELES. Parts of animals. Movement of animals; Progression of animals. Trad.: A. L. Peck, London: The Loeb Classical Library, 1961.

ARISTÓTELES. Acerca del cielo. Meteorológicos. Trad. e notas de M. Candel, Madri: Biblioteca Clásica Gredos, 1996.

ARISTÓTELES. As partes dos animais. Livro I. Trad. e comentários de L. Angioni, Campinas: Cadernos de História e Filosofia da Ciência, vol. 9, série 3, n. especial, 1999. 
ARISTÓTELES. Acerca de la generación y la corrupción. Tratados Breves de Historia Natural. Trad. e notas de E. La Croce, e A. B. Pajares, Madri: Biblioteca Clásica Gredos, 1998.

ARISTÓTELES. Partes de los animales; Marcha de los animales; Movimiento de los animales. Trad. e notas de E. J. Sánchez-Escariche, e A. A. Miguel, Madri: Biblioteca Clásica Gredos, 2000.

ARISTÓTELES. Metafísica. Trad. e notas de T. C. Martínez, Madri: Biblioteca Clásica Gredos, 2006.

BOGEN, James. Fire in the belly: Aristotelian elements, organisms, and chemical compounds. In: LEWIS, A. F; BOLTON R. (ed.) Form, Matter, and Mixture in Aristotle. . Oxford, UK: Blackwell Publishers, 1996, p. 183-215.

FURTH, Montgomery. Substance, form and psyche: an Aristotelian metaphysics. Cambridge: Cambridge University Press, 1988.

NUSSBAUM, Martha C. Aristotle on teleological explanation. In: NUSSBAUM, Martha C. Aristotle's De motuanimalium text with translation, commentary, and interpretive essays. Princeton: Princeton University Press, 1985, p. 59-99.

PELLEGRIN, Pierre. Aristote, partes des animaux: Livre I, Paris - Introduction. GFFlammarion, 1995.

WATERLOO, Sarah. Nature, change and agency in Aristotle's Physics. Oxford: Clarendon Press, 1982.

WHITING, Jennifer E. Living bodies. In: NUSSBAUM, M; RORTY, A (eds.) Essays on Aristotle's De anima. Oxford: Clarendon Press, 1992, p. 75-91.

Recebido: 27/6/2018

Aceito: 04/7/2019 
CARVALHO, R. R. 